\title{
DESAIN SARANA BAWA PERALATAN PANAHAN UNTUK KEPERLUAN LATIHAN RUTIN
}

\author{
Royke Vincentius F \\ Staff Pengajar Program Studi Desain Produk, Jurusan Desain \\ Politeknik Negeri Samarinda \\ Email: rvincentius@gmail.com \\ Cicik Okta P \\ Mahasiswa Program Studi Desain Produk, Jurusan Desain \\ Politeknik Negeri Samarinda
}

\begin{abstract}
ABSTRAK
Panahan telah berkembang dari fungsinya sebagai keahlian untuk bertahan hidup (berburu), menjadi sarana berperang, menjadi seni, menjadi bentuk olahraga dan kini telah berkembang lebih jauh menjadi sebuah identitas gaya hidup.

Di Samarinda panahan yang tadinya hanya merupakan salah satu bentuk olahraga yang dikembangkan untuk tujuan kompetisi, kini berkembang menjadi sebuah bagian gaya hidup dan hoby sebagaimana beberapa olahraga lain seperti renang dan basket.

Perubahan fungsi panahan tersebut berpengaruh pula pada perubahan jenis kebutuhan sarana bawa. Saat ini belum terdapat sarana bawa peralatan olahraga panahan untuk keperluan latihan rutin.

Untuk keperluan latihan rutin dengan studi kasus penggemar olahraga panahan di Samarinda, dibuatlah desain sarana bawa peralatan panahan berbentuk softcase. Dengan sarana bawa ini, peralatan panahan dapat dibawa dalam bentuk terurai untuk kemudian dirakit saat sampai di tempat latihan. Sarana bawa semacam ini sesuai untuk digunakan untuk keperluan latihan yang lebih membutuhkan sarana bawa yang nyaman digunakan. Kata kunci: Panahan, sarana bawa, latihan, softcase.
\end{abstract}

\begin{abstract}
Archery had transformed from its original purposes as a skill to hunt, into a war weapon, into an art, into a sport; and today archery had transform futher into a part of lifestyle and as a hobby.

Same case happens in Samarinda; where archery had turns from a sport into a hobby. The transformation had impacted the kind of purposes the archery devices carrier need to fullfil. At the moment a carrying device specialized for routine training purposes is not existed yet. This project purposes is to create a carrying device specialized for routine training use.

For those purposes a softcase carrier is designed. Softcase carrier is quite suitable and pactical for informal purposes as routine training.

Keywords: archery, carrying device, bag, training, softcase.
\end{abstract}


Royke Vincentius F, Cicik Okta P, Desain Sarana Bawa Peralatan Panahan Untuk Keperluan Latihan Rutin

\section{Pendahuluan}

Memanah merupakan senjata yang awalnya digunakan untuk berburu, bertahan hidup dan berkompetisi (Johnson, 2014). Di beberapa negara timur seperti Jepang misalnya olahraga ini bahkan digunakan sebagai media melatih aspek spiritualitas manusia (Herrigel, 1953). Namun kini Panahan berubah menjadi salah satu cabang olahraga yang banyak digemari. Pada Olimpiade London tahun 2012, olahraga ini bahkan menjadi salah satu olahraga yang paling banyak ditonton (Johnson, 2014). Di Indonesia panahan termasuk olahraga yang populer, termasuk di Kota Samarinda Provinsi Kalimantan Timur. Hal ini terbukti dengan banyaknya kejuaraan-kejuaraan panahan di Indonesia.

Cabang olahraga panahan adalah satu dari sekian banyak olahraga yang simple, tetapi teknis yang cukup rumit. Panahan merupakan olahraga yang melatih fokus, kesabaran, dan ketenangan. Peralatan utama dari olahraga ini hanya terdiri dari busur dan anak panahnya. Namun pada perkembangannya, terutama untuk keperluan olahraga terdapat berbagai asesoris yang dapat ditambahkan untuk menambahkan keakuratan panah dalam mencapai sasaran.

Di Samarinda cabang olahraga Panahan dibawahi oleh Pencab Perpani Samarinda. Terdapat dua klub memanah di Samarinda, yaitu Club Black Bee dibawah binaan Pemprov dengan kurang lebih 40 peserta dan Elang Borneo Archery Club yang merupakan klub swasta. Dalam kejuaraan panahan terdapat 3 tingkatan yaitu Junior, Senior dan 3 Nomor Tanding. Nomor tanding tersebut memiliki 3 divisi yaitu divisi rikab, kompon, dan ronde nasional/standart bow. Menurut Hanafiah ketua cabang olahraga panahan di Samarinda, olahraga panahan mulai popular sekitar tahun 1981. Samarinda telah meraih medali pada kejuaraan Asean games 1995, Asean Games Hiroshima 1994, kejuaraan dunia di Panahan Jakarta ,PON dan yang terakhir pada Olimpiade room. 12
Untuk berlatih biasanya pemain olahraga panahan menggunakan busur jenis standar. Peralatan tersebut biasanya dibawa dengan tas seadanya. Tas khusus membawa peralatan panahan sebenarnya telah ada, namun bentuknya berupa hardcase bag dan harganya pun masih cukup mahal. Tas khusus tersebut juga dianggap berukuran terlalu besar dan kurang praktis untuk keperluan latihan rutin. Wawancara yang dilakukan terhadap anggota klub Black Bee dan Elang Borneo menyebutkan hampir semua anggota biasanya menggunakan tas sekolah atau tas seadanya untuk membawa peralatan panahan tersebut. Saat ini belum ada tas berjenis softcase yang khusus digunakan untuk membawa peralatan panahan. Kuisioner yang dibuat dan disebarkan pada anggota kedua klub tersebut menyebutkan bahwa 90\% responden membutuhkan sarana bawa peralatan panahan untuk latihan sehari-hari. Sarana bawa peralatan panahan yang diinginkan adalah saran bawa yang praktis, fleksibel, namun dapat menjaga peralatan panahan tetap aman. Mereka juga mengharapkan sarana tersebut tersedia dengan harga terjangkau.

\section{Metode Perancangan}

Proses perancangan Sarana bawa Panahan ini menggunakan Metode perancangan sebagaimana dikembangkan oleh Vinod Goel (1995). Secara umum proses perancangan akan dimulai dengan penetapan permasalahan desain, kemudian dilanjutkan dengan proses preliminary desain yang meliputi tinjauan pustaka, observasi dan analisa; kemudian dilanjutkan dengan proses pencarian alternatif desain; dan kemudian memilih satu alternatif yang terbaik dan membuat gambar kerjanya.

\section{Pembahasan \\ 3.1. Segmentasi Pasar}

Segmentasi pasar yang dituju oleh produk Sarana Bawa Peralatan Panahan ini adalah anggota klub panahan, dengan jenis 
Vol. 4, No. 2, April 2017

kelamin laki-laki maupun perempuan, dengan rentang usia antara 17 sampai 40 tahun, dari strata sosial menengah keatas mengingat peralatan panahan ini memiliki harga yang cukup mahal. Studi kasus dilakukan pada area Samarinda.

\subsection{Analisis Aktivitas dan Kebutuhan}

Jenis Busur yang digunakan adalah jenis busur standar berukuran 54" sampai dengan 68", jenis busur berukuran sebagaimana disebutkan merupakan bususr yang paling banyak digunakan oleh para anggota klub. Busur Tersebut dapat diurai menjadi 3 bagian. Dalam perancangan sarana bawa ini diberikan batasan bahwa busur nantinya akan dibawa dalam keadaan terurai dan kemudian dirakit ditempat latihan.
Peralatan dan perlengkapan lain yang harus dibawa antara lain:

1. Busur Panah

2. Anak Panah

3. Stabilizer

4. Bag Quifer (tempat anak panah)

5. Bow stand (tempat busur)

6. Alat pengaman : pelindung jari, pelindung lengan, pelindung tangan.

7. Tang

8. Obeng

9. Kunci pas ukuran $10,11,12$

10. Kunci L 10,11,12

11. Cutter

12. Lem

Studi aktivitas dilakukan pada anggota klub panahan ketika akan latihan; aktivitas tersebut kemudian akan memunculkan kebutuhan fasilitas seperti ditampilkan pada tabel berikut :

Tabel 1. Studi Aktivitas

\begin{tabular}{|c|c|c|c|}
\hline No & Aktivitas & Komponen & Fasilitas \\
\hline 1 & $\begin{array}{c}\text { Mengambil dan } \\
\text { menyimpan alat } \\
\text { pengaman }\end{array}$ & $\begin{array}{l}\text { Pengaman bahu, pengaman tangan . } \\
\text { pengaman jari }\end{array}$ & $\begin{array}{c}\text { Area } \\
\text { Penyimpanan } \\
\text { pengaman } \\
\text { bahu, tangan } \\
\text { dan jari }\end{array}$ \\
\hline 2 & $\begin{array}{l}\text { Mengambil dan } \\
\text { menyimpan } \\
\text { Limbs, Hendle } \\
\text { dan tali }\end{array}$ & Limbs, Hendle dan tali & $\begin{array}{c}\text { Area } \\
\text { pengaman } \\
\text { limbs, Hendle } \\
\text { dan tali }\end{array}$ \\
\hline 3 & $\begin{array}{c}\text { Mengambil dan } \\
\text { menyimpan } \\
\text { Peralatan } \\
\text { penunjang } \\
\text { perakitan }\end{array}$ & $\begin{array}{l}\text { Tang, Obeng, Kunci pas ukuran } \\
\text { 10,11,12, Kunci L 10,11,12 Kater, Lem }\end{array}$ & $\begin{array}{c}\text { Area } \\
\text { penyimpanan } \\
\text { peralatan } \\
\text { penunjang } \\
\text { perakitan }\end{array}$ \\
\hline 4 & $\begin{array}{c}\text { Mengambil dan } \\
\text { menyimpan } \\
\text { Stabilizer }\end{array}$ & Stabilizer & $\begin{array}{c}\text { Area } \\
\text { penempatan } \\
\text { Stabilizer }\end{array}$ \\
\hline 5. & $\begin{array}{c}\text { Mengambil dan } \\
\text { menyimpan bag } \\
\text { quifer }\end{array}$ & $\begin{array}{c}\text { Bag quifer/ tempat anak panah saat } \\
\text { dilapangan }\end{array}$ & $\begin{array}{c}\text { Area } \\
\text { Penempatan } \\
\text { Bag quifer }\end{array}$ \\
\hline 6 & $\begin{array}{l}\text { Mengambil dan } \\
\text { menyimpan bow } \\
\text { stand, pembidik }\end{array}$ & Bow stand & $\begin{array}{c}\text { Area } \\
\text { penempatan } \\
\text { bow stand }\end{array}$ \\
\hline 7 & $\begin{array}{l}\text { Mengambil dan } \\
\text { menyimpan } \\
\text { Anak panah }\end{array}$ & $\begin{array}{c}\text { Anak panah saat pembawaan / } \\
\text { penyimpanan }\end{array}$ & $\begin{array}{c}\text { Area } \\
\text { penempatan } \\
\text { anak panah }\end{array}$ \\
\hline 8. & $\begin{array}{l}\text { Memasukkan } \\
\text { botol minum }\end{array}$ & Botol minum & $\begin{array}{c}\text { Kantong pada } \\
\text { tas }\end{array}$ \\
\hline
\end{tabular}


Royke Vincentius F, Cicik Okta P, Desain Sarana Bawa Peralatan Panahan Untuk Keperluan Latihan Rutin

\subsection{Analisis Ergonomi}

Berat maksimum beban angkat yang digunakan adalah batas maksimum wanita yaitu $16 \mathrm{~kg}$. Batas maksimum wanita digunakan karena memang produk ini nantinya akan diperuntukkan bagi pria maupun wanita, karenanya harus dapat diangkat oleh jenis kelamin yang dianggap paling lemah, dalam hal ini jenis kelamin wanita.

Aspek ergonomi lain jug dipertimbangkan agar produk yan dirancang dapat digunakan dengan nyama Aspek tersebuat antara lain aspek tinggi ta dimana tinggi tas yang diharapkan tida boleh lebih tinggi dari tengkuk wanit: Bagian tas yang menempel di tubuh bain pada punggung maupun pundak harus diberi bantalan agar tidak menyakiti bagian tubuh yang mengalami kontak langsung dengan tas. Bahan yang digunakan juga harus memperhatikan aspek ergonomis seperti anti iritasi dan tidak melukai bagian tubuh.

\subsection{Analisis Anthropometri}

Agar tas nyaman digunakan maka ukurannya pun harus disesuaikan dengan penggunanya. Untuk ukuran anthropometris digunakan standard Hongkong yang dianggap mewakili juga ukuran tubuh dan perawakan orang Indonesia pada umumnya. Berikut ukuran anthropometri yang digunakan untuk menentukan dimensi tas yang berkaitan dengan aspek kenyamanan :

\section{Lebar bahu}

Dimensi lebar bahu untuk menentukan panjang pada tas agar dapat digunakan dengan nyaman. Ukuran yang dijadikan acuan adalah gender wanita 5 persentile yaitu $380 \mathrm{~mm}$ dengan ukuran bahu $5 \%$ wanita maka dapat mengakomodir pengguna yang lebih kecil maupun yang lebih besar. Nilai ini ditambah toleransi tebal material $20 \mathrm{~mm}$ sehingga ukuran lebar tas yang diaplikasikan pada produk adalah maksimal $400 \mathrm{~mm}$.

\begin{tabular}{|l|c|c|c|c|c|c|}
\hline Dimensi & \multicolumn{3}{|c|}{ Laki-laki } & \multicolumn{3}{c|}{ Perempuan } \\
tubuh & $5 \%$ tile & $50 \%$ tile & $95 \%$ tile & $5 \%$ tile & $50 \%$ tile & $95 \%$ tile \\
\cline { 2 - 7 } & 380 & 425 & 470 & 335 & 375 & 425 \\
\hline $\begin{array}{c}\text { Lebar } \\
\text { bahu }\end{array}$ & & & & & & \\
\hline
\end{tabular}

Sumber : Nurmianto 1991

2. Panjang Bahu ke Pinggang

Dimensi panjang bahu ke punggung digunakan untuk menentukan tinggi pada tas agar dapat digunakan dengan nyaman. Ukuran yang dijadikan acuan adalah ukuran gender Pria $95 \%$ yaitu $655 \mathrm{~mm}$ agar dapat mengakomodir semua bawaan dengan dimensi yang lebih panjang. Sehingga ukuran panjang tas yang diaplikasikan pada produk adalah minimal $655 \mathrm{~mm}$. Tinggi bahu pada posisi duduk pria $95 \%$ adalah ukuran tinggi tas minimal $655 \mathrm{~mm}$. Dalam pengertian yang lain, tinggi tas boleh melebihi ukuran tersebut karena dalam terdapat toleransi $95 \mathrm{~mm}$ sebagai perlindungan tidak rusaknya barang yang ada didalam. Pada perancangan ini, tinggi tas yang didesain adalah $655 \mathrm{~mm}$ ditambah toleransi $95 \mathrm{~mm}$ sehingga tinggi tas maksimal menjadi $750 \mathrm{~mm}$.

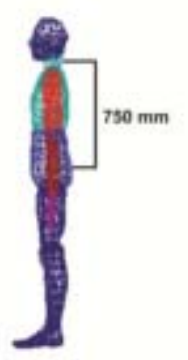


Vol. 4, No. 2, April 2017

Tabel 3. Ukuran Panjang Bahu ke Punggung

\begin{tabular}{|c|c|c|c|c|c|c|}
\hline Dimensi tubuh & \multicolumn{3}{|c|}{ Laki-laki } & \multicolumn{3}{c|}{ Perempuan } \\
\cline { 2 - 7 } & $5 \%$ tile & $50 \%$ tile & $95 \%$ tile & $5 \%$ tile & $50 \%$ tile & $95 \%$ tile \\
\hline $\begin{array}{c}\text { Panjang bahu ke } \\
\text { punggung }\end{array}$ & 555 & 605 & 655 & 165 & 230 & 295 \\
\hline
\end{tabular}

Sumber : Nurmianto, 1991

\section{Lebar Tangan}

Ukuran lebar tangan akan dijadikan acuan untuk menentukan ukuran yang berkaitan dengan handle untuk menjinjing tas. Gender yang digunakan adalah pria $95 \%$ agar dapat mengakomodir ukuran pengguna secara universal. Tebal tangan pria $95 \%=$ ukuran lebar celah tas maksimal $=9 \mathrm{~cm}$. Nilai ini ditambah dengan tebal sarung tangan $1 \mathrm{~cm}$ sehingga ukurannya menjadi $10 \mathrm{~cm}$.

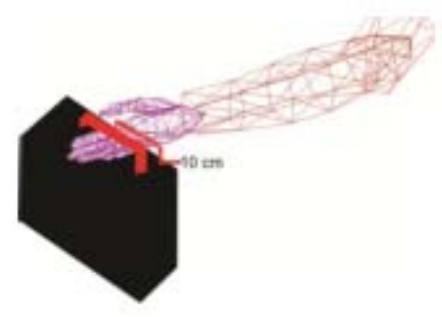

\subsection{Analisis Konfigurasi}

Analisis Konfigurasi dilakukan untuk mendapatkan konfigurasi yang paling sesuai dan memudahkan penggunaan sarana bawa alat panahan tersebut. Berikut adalah satu konfigurasi yang dianggap paling sesuai.

Pada konfigurasi ini limbs dan handle terdapat di paling belakang karena memerlukan ruang yang relatif banyak agar tidak merusak peralatan tersebut. pada bagian kirinya terdapat tempat yang akan digunakan sebagai penempatan tabung anak panah dan disebelahnya lagi terdapat kantong yang digunakan untuk menyimpan stabilizer dan bowstand dibalik kantong bagian ini terdapat kantong yang akan digunakan untuk menyimpan peralatan penunjang perakitan. Pada bagian sebelah

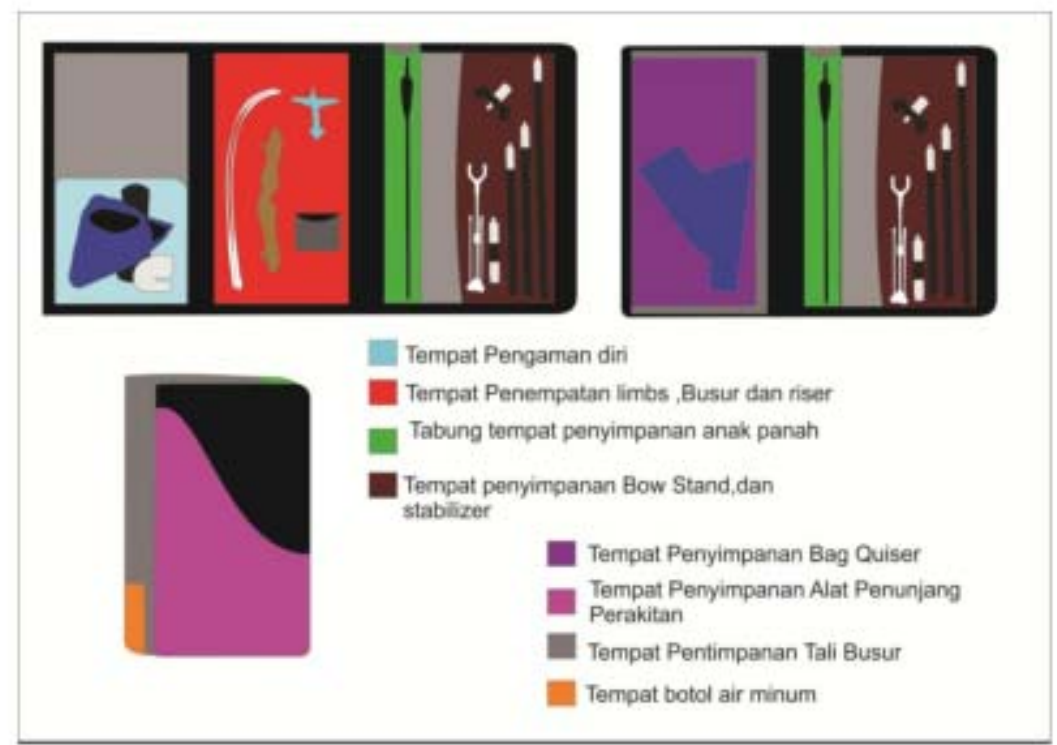


Royke Vincentius F, Cicik Okta P, Desain Sarana Bawa Peralatan Panahan Untuk Keperluan Latihan Rutin

kanan limbs dan handle terdapat kantong penyimpanan alat pengaman diri, dan dibalik bagian ini terdapat kantong yang digunakan untuk penyimpanan bag quifer, sedangkan pada bagian kiri dapat digunakan sebagai tempat penyimpanan peralatan penunjang perakitan busur.

Konfigurasi ini dianggap paling sesuai karena peletakan peralatan panahan sesuai dengan kebutuhan tanpa mengganggu perlengkapan satu dengan yang lainnya dan penempatan didasarkan aktivitas yang sesuai untuk dilakukan. Tidak lagi bersusah payah dalam mencari bagian-bagian yang akan dirakit karena penempatan telah terorganisir.

\subsection{Analisis Sistem}

A. Sistem Kuncian

Sistem Kuncian yang akan digunakan dalam pembuatan produk sarana bawa peralatan panahan ini adalah

a. Resleting sebagai sistem kuncian pada bagian tas. Resleting yang digunakan resleting jenis resleting coil yaitu jenis resleting dengan gerigi berbahan polyster atau nilon. Karena pemasangan resleting jenis ini lebih mudah dibanding jenis resleting lainnya.

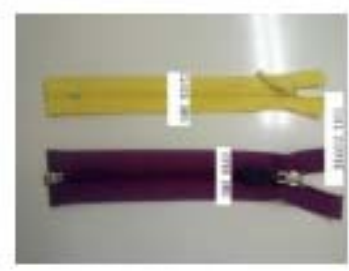

b. Hook and Loop digunakan sebagai kuncian pada penyimpanan peralatan panahan sehingga kebutuhan yang digunakan mudah disesuaikan jika menggunakan sistem Hook and Loop ini.

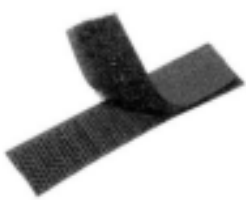

c. Metal Buckle sebagai penguncian tutup tas bagian depan karena metal buckle kuat jika digunakan sistem penguncian sehingga tidak mudah terlepas.

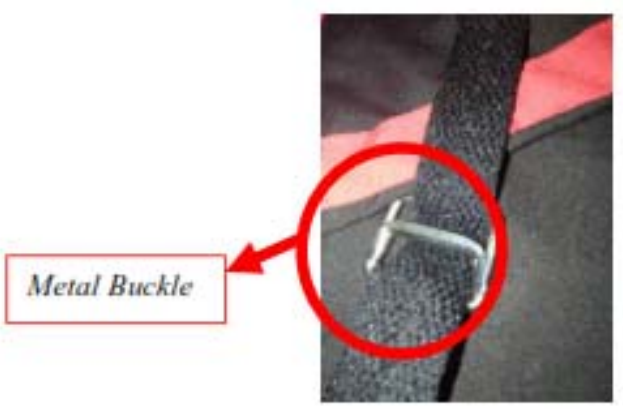

B. Sistem Sambungan

Sistem Sambungan digunakan untuk menyambung bagian-bagian dari produk yang terpisah agar dapat digunakan. Sistem yang dapat digunakan dalam pembuatan produk sarana bawa peralatan panahan ini adalah Plastic buckle digunakan sebagai penyambung antara tali tas dengan tali webbing tape sehingga panjang tali dapat disesuaikan dengan kebutuhan pengguna. Jika dibanding dengan metal buckle maka lebih efisien digunakan sebagai penyambung pada tali tas.

Metal Buckle

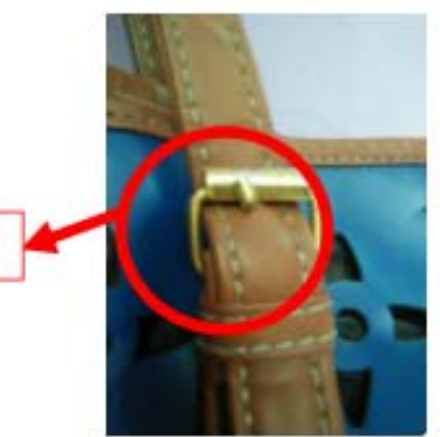


Vol. 4, No. 2, April 2017

C. Sistem Jahitan

Jahitan yang akan digunakan pada pembuat sarana bawa peralatan panahan ini adalah

a. Sistem jahitan pada tas bagian luar menggunakan jahitan Kunci karena jahitan ini sangat sesuai untuk menjahit kain yang cukup tebal karena jahitan jenis ini cukup kuat. Jahitan jenis ini memberikan bentuk yang sama pada sisi atas dan bawahnya. Jahitan kunci merupakan jahitan yang susah untuk dilepas.

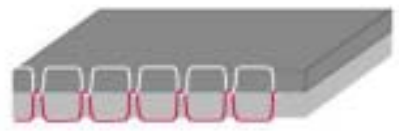

\section{Sumber : https://www.guetermann.com}

b. Sistem jahitan pada kantong tas menggunakan Jahitan Tumpang. Jahitan ini pada umumnya mulai dengan dua helai kain yang di tumpang satu sama lain dan disambung dekat bagian pinggir, dengan satu baris jahitan atau lebih.

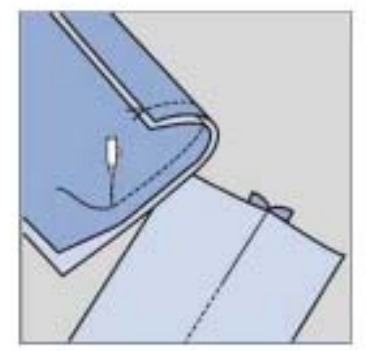

Sumber : http://www.coatsindustrial.com

c. Sistem Jahitan pada tali tas menggunakan jahitan Kunci karena jahitan ini sangat sesuai untuk menjahit kain yang cukup tebal karena jahitan jenis ini cukup kuat.

\section{Sistem Grafis}

Finishing grafis menjadi pilihan bagi pemberian aksen pada produk sehingga produsen dapat menyampaikan maksudnya pada pengguna seperti pemberian label merk, kegunaan produk yang dikhususkan dan lainlainnya. Dalam Finishing grafis terdapat beberapa jenis yang dapat di aplikasikan.
Namun untuk proyek perancangan ini dipilih Bordir. Pengaplikasian grafis dengan cara Bordir dianggap paling kuat dan tahan lama serta biaya produksinyapun tidak tinggi.

\subsection{Analisis Material}

Analisis material dilakukan agar dapat menemukan material yang tepat untuk diaplikasikan pada produk. Busur yang digunakan biasanya dibuat dari kayu Maple dengan lapisan Melamine. Sementara berbagai asesoris lainnya dibuat dari bahan alumunium dan besi. Material yang digunakan nantinya harus dapat melindungi jenis-jenis material sebagaimana disebutkan diatas. Namun sebagaimana dipaparkan Ashby dan Johnson (2014), material untuk benda desain produk bukan sekedar harus memenuhi aspek fungsi tapi juga aspek simbolis dan dekoratif.

\section{A. Badan Tas}

Jumlah lapisan material yang diinginkan untuk badan tas adalah 3 lapis, karena material dengan 3 lapisan memiliki kekuatan yang lebih dan juga memungkinkan untuk menambahakan elemen pelindung dan penambah kenyamanan yang memang menjadi syarat untuk produk ini. Material bagian luar harus tahan terhadap air dan kuat, material pada bagian tengah dapat melindungi sarana peralatan panahan yang ada didalam juga dapat member kenyamanan terhadap pengguna atau tidak menyakiti pengguna, sedangkan material bagian dalam dapat menahan air dan dapat melindungi sarana didalam agar tidak tergesek satu sama lain sehingga tidak akan terjadi kerusakan.

Kain bagian luar yang akan digunakan adalah kain kanvas. Kain kanvas digunakan karena memiliki serat yang sangat kuat lebih kuat dibanding cordura dan tebal sehingga tidak mudah rusak/robek, memiliki ketahanan terhadap air selain itu pemilihan warna yang bervariasi dan harga yang terjangkau menjadi salah satu alasan pemilihan material bagian luar ini. 
Royke Vincentius F, Cicik Okta P, Desain Sarana Bawa Peralatan Panahan Untuk Keperluan Latihan Rutin

Material bagian tengah digunakan adalah Polyfoam karena Polyfoam memiliki sifat yang kedap air, memiliki jenis ketebalan yang bervariasi dan harga Polyfoam lebih terjangkau dibanding Busa Eva/Busa Ati, sehingga Polyfoam dapat memberi kenyamanan bagi pengguna saat penggunaan dan dapat melindungi perlengkapan panahan yang ada didalam sehingga tidak mudah rusak.

Material yang akan dilindungi oleh lapisan dalam tas ini adalah kayu Maple yang di Melamine, Alumunium dan Besi. Menurut Lefteri (2014), Maple sebenarnya merupakan jenis kayu yang tahan abrasi, namun karena material ini dilapis dengan melamine maka dibutuhkan jenis bahan yang lembut dan tidak berserat kasar. Demikian juga dengan jenis material alumunium. Material yang akan digunakan pada bagian dalam tas adalah kain furing karena kain furing memiliki sifat lembut, lebih tahan terhadap resapan air dibandingkan kain katun dan juga kain furing dapat didaur ulang sehingga dapat mengurangi limbah yang ada dilingkungan.

\section{B. Tali Tas}

Untuk bagian tali tas juga diinginkan tali yang memiliki tiga lapisan. Material Tali bagian luar yang akan digunakan adalah kain kanvas. Kain kanvas digunakan karena menyesuaikan material body tas, kain kanvas memiliki sifat berserat yang sangat kuat lebih kuat daripada kain cordura dan tebal sehingga tidak mudah rusak/robek, memiliki ketahanan terhadap air dan memiliki banyak pilihan warna. Material bagian tengah digunakan adalah Polyfoam karena Polyfoam memiliki sifat yang kedap air, memiliki jenis ketebalan yang bervariasi dan harga Polyfoam lebih terjangkau dibanding Busa Eva/Busa Ati, sehingga Polyfoam dapat memberi kenyamanan bagi pengguna saat penggunaan, terutama pada bagian bahu. Untuk Bagian dalam digunakan kain kanvas, untuk menyesuaiakan dengan material yang

digunakan pada badan tas dan tali bagian luar.

\subsection{Analisis Bentuk}

Bentuk yang akan digunakan pada tas panahan ini dengan mengambil desain Modern karena gaya desain Modern dengan prinsip form follow function, dimana bentuk harus mengikuti fungsi. Sarana bawa peralatan panahan ini sangat mengedepankan masalah fungsi sehingga gaya desain ini dianggap paling sesuai untuk produk ini. Pada bentuknya akan digunakan bentukbentuk sederhana dan tegas.

\subsection{Analisis Warna}

Analisis warna dilakukan agar mendapatkan warna yang sesuai dengan desain produk yang akan dibuat. Pemilihan warna akan dilakukan berdasarkan pengamatan terhadap pengguna sehingga produk yang akan dibuat sesuai dengan pengguna produk tersebut. Warna utama yang akan digunakan pada produk ini menggunakan warna netral sehingga sesuai pengguna dengan gender wanita dan pria. Warna netral berikut yang dapat digunakan pada Warna utama produk yaitu Hitam yang memberi kesan keanggunan, kemakmuran, dan kecanggihan selain kelebihan tersebut warna hitam sesuai dengan semua gender serta warna hitam jika digunakan di alam tidak mudah terlihat kotor. Dalam sebuah produk akan lebih baik jika terdapat warna aksen yang digunakan. Warna aksen yang dapat digunakan pada produk ini yaitu Merah karena warna merah memberi kesan Semangat, Keberanian dan Kekuatan sehingga dapat memicu semangat dari para peserta pelatihan olahraga panahan. 
IV. Pengembangan Desain

4.1. Alternatif Desain

a. Alternatif Desain 1

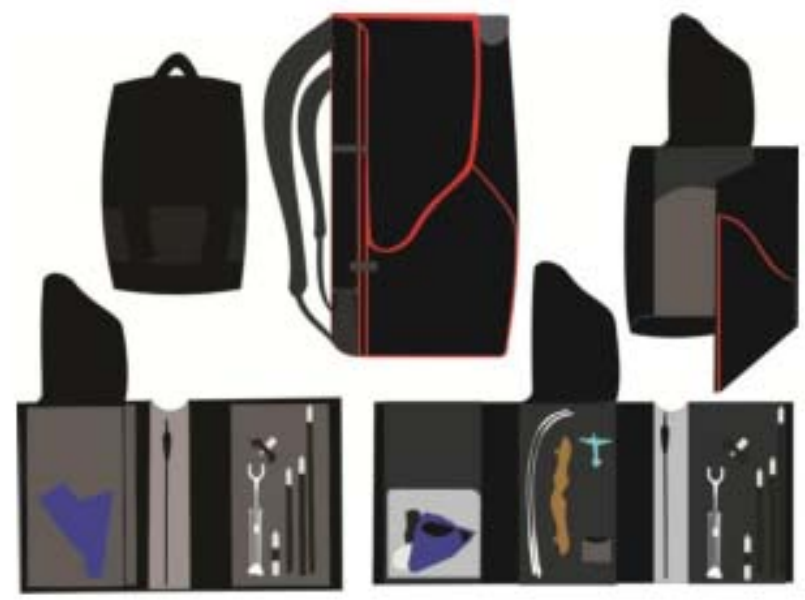

b. Alternatif Desain 2
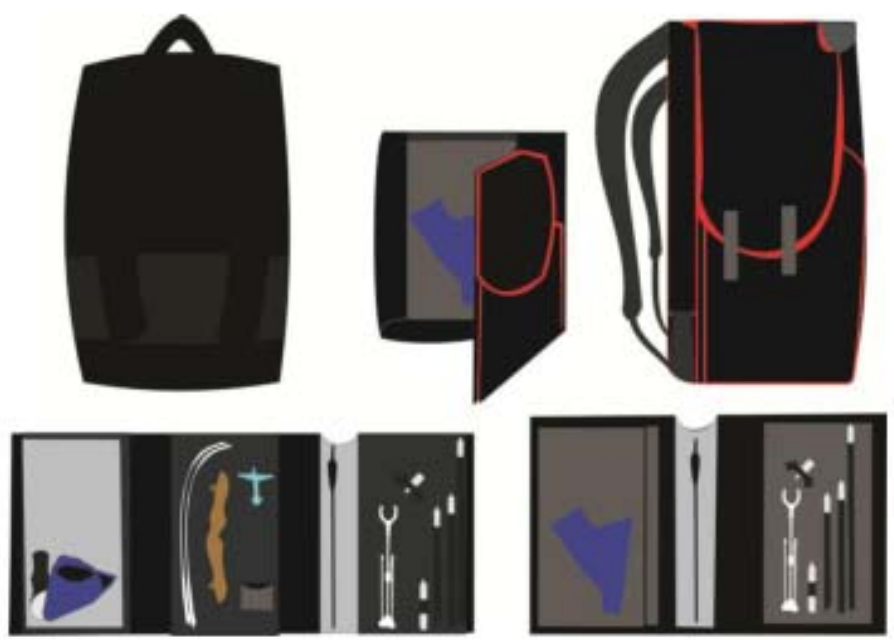

c. Alternatif Desain 3

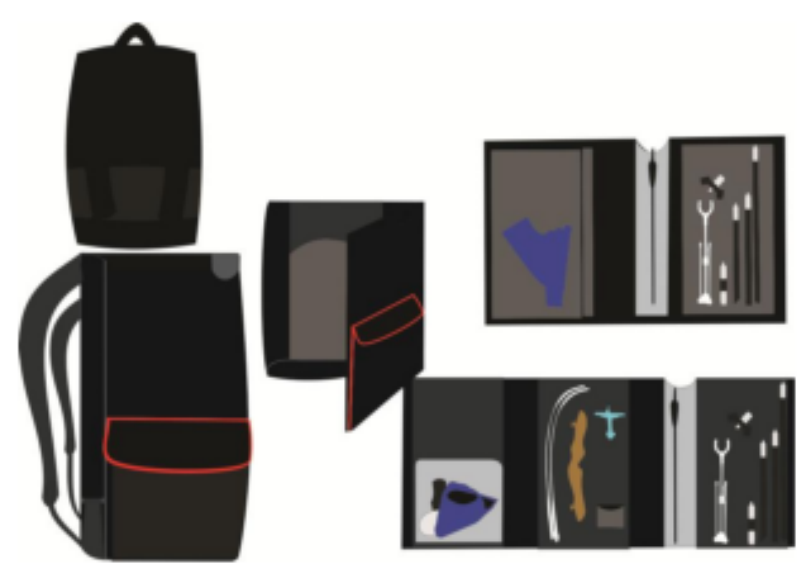


Royke Vincentius F, Cicik Okta P, Desain Sarana Bawa Peralatan Panahan Untuk Keperluan Latihan Rutin

d. Alternatif Desain 4
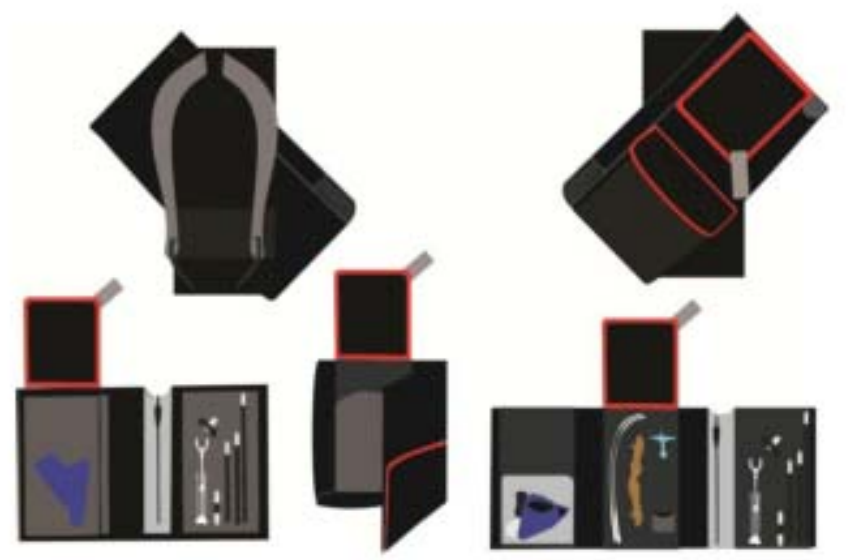

e. Alternatif Desain 5

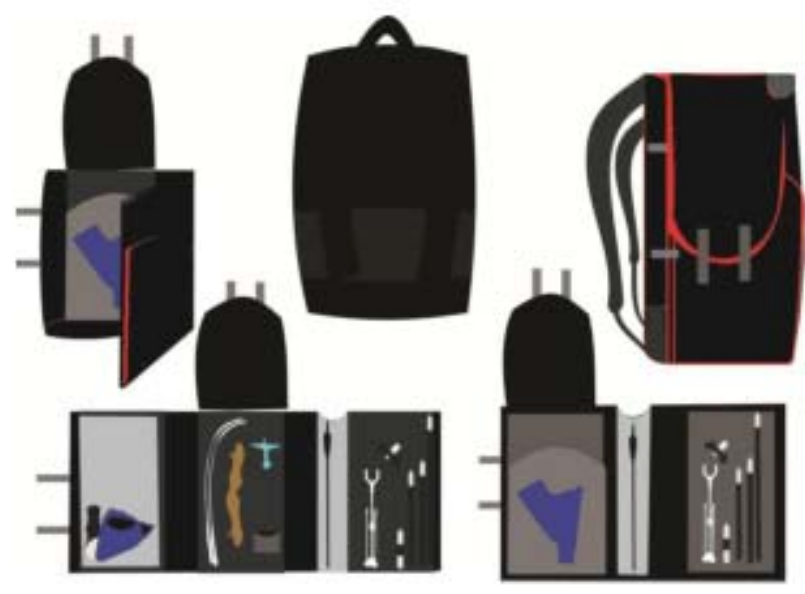

4.2. Pengembangan Desain

a. Pengembangan Desain 1

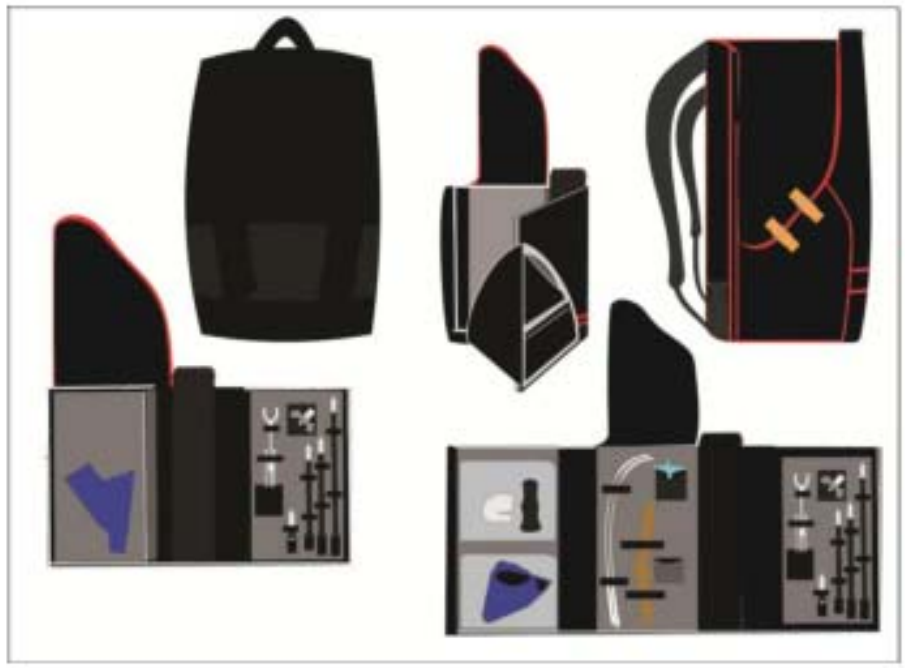


b. Pengembangan Desain 2

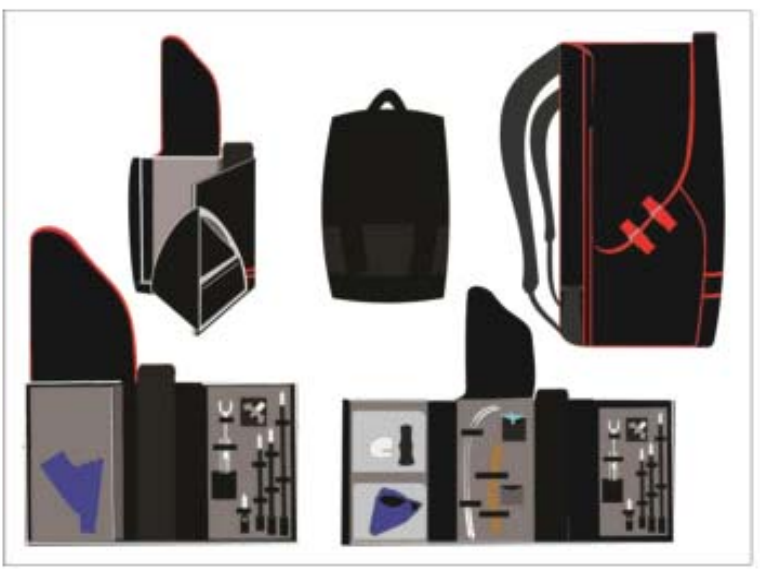

c. Pengembangan Desain 3

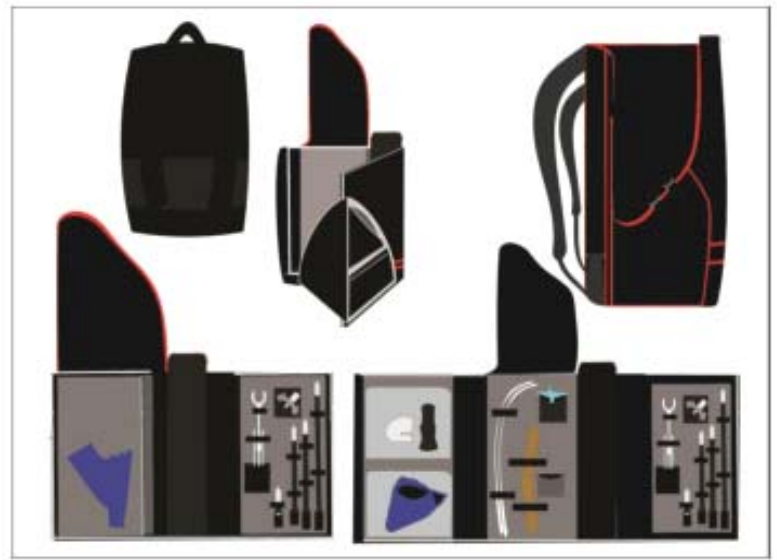

\subsection{Final Desain}

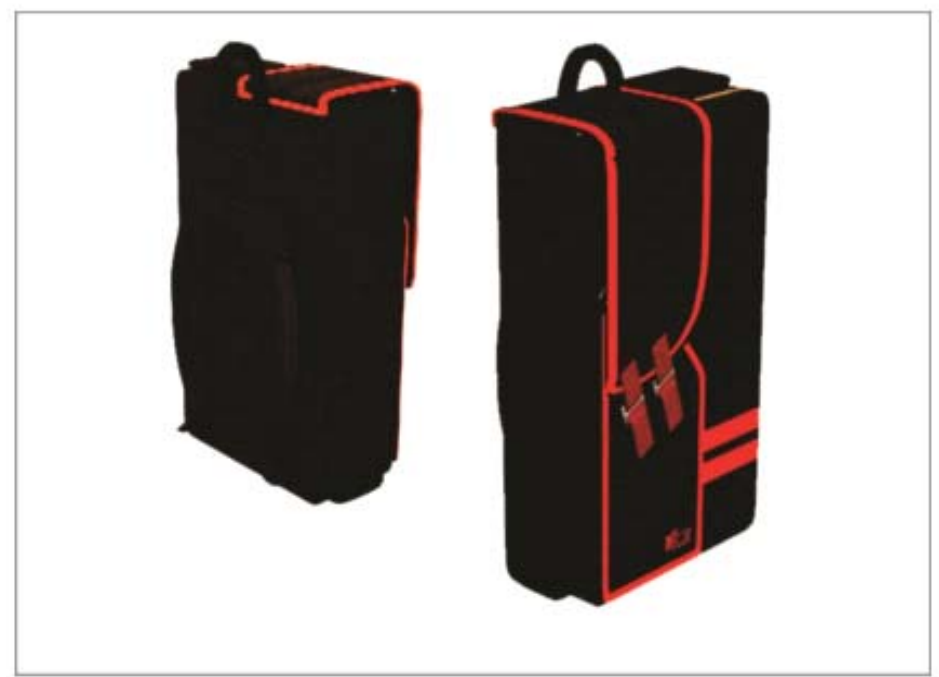


Royke Vincentius F, Cicik Okta P, Desain Sarana Bawa Peralatan Panahan Untuk Keperluan Latihan Rutin

\section{Kesimpulan dan Saran}

\subsection{Kesimpulan}

Untuk membuat sarana bawa peralatan panahan yang baik dibutuhkan konfigurasi yang sesuai, bahan yang tepat dan desain yang juga memperhatikan aspek ergonomi. Konfigurasi yang sesuai dibutuhkan karena sarana bawa ini dibawa dalam bentuk terurai. Konfigurasi yang baik memudahkan pengguna dalam proses perakitan. Bahan yang sesuai diperlukan karena fungsi bahan selain juga sebagai elemen pelindung juga sebagai elemen estetis. Aspek ergonomi penting diperhatikan, karena item yang harus disimpan dalam tas ini cukup banyak macam dan jumlah serta ukurannya. Tas harus didesain sedemikian rupa sehingga nyaman saat digunakan.

\subsection{Saran}

Untuk proyek perancangan berikutnya terbuka peluang untuk menambahkan aspek emosional dalam desain sarana bawa panahan tersebut. Sarana bawa ini bisa diberi muatan makna seperti tradisional, identitas komunitas maupun aspek-aspek emosional desain yang lainnya.

\section{Daftar Pustaka}

Ashby, Michael; Johnson, Kara. 2014. Materials and Design. Oxford : Elsevier. Johnson, Teresa. 2014. Archery Fundamentals (2nd edition). USA : Human Kinetics. Goel, Vinod. 1995. Sketches of Thouht. Massachusetts : MIT Press. Herrigel, Eugen. 1953. Zen in the Art of Archery. Penerbit : N.A. Lefteri, Chris. (2014). Materials for Design. London : Laurence King Publisher. 